\title{
Article \\ Effect of COVID-19 Pandemic on Hepatocellular Carcinoma Diagnosis: Results from a Tertiary Care Center in North-West Italy
}

\author{
Davide Giuseppe Ribaldone $\left.{ }^{1, *}++^{(}\right)$, Gian Paolo Caviglia ${ }^{1,+}\left(\mathbb{D}\right.$, Silvia Gaia ${ }^{2}$, Emanuela Rolle ${ }^{2}$, Alessandra Risso ${ }^{1}$, \\ Daniela Campion ${ }^{2}$, Paola Rita Brunocilla ${ }^{2}$, Giorgio Maria Saracco ${ }^{1,2}$ D and Patrizia Carucci ${ }^{2, *}$ \\ 1 Department of Medical Sciences, University of Turin, 10100 Turin, Italy; gianpaolo.caviglia@unito.it (G.P.C.); \\ alessandrarisso82@gmail.com (A.R.); giorgiomaria.saracco@unito.it (G.M.S.) \\ 2 Division of Gastroenterology, Città della Salute e della Scienza University-Hospital, 10100 Turin, Italy; \\ silvia.gaia74@gmail.com (S.G.); emanurolle@inwind.it (E.R.); daniela.campion@gmail.com (D.C.); \\ paolabrunocilla@gmail.com (P.R.B.) \\ * Correspondence: davidegiuseppe.ribaldone@unito.it (D.G.R.); pcarucci@cittadellasalute.to.it (P.C.); \\ Tel.: +39-11-633-3615 (D.G.R.); Fax: +39-11-633-3970 (D.G.R.) \\ + These authors contributed equally to this work.
}

check for updates

Citation: Ribaldone, D.G.; Caviglia, G.P.; Gaia, S.; Rolle, E.; Risso, A.;

Campion, D.; Brunocilla, P.R.; Saracco, G.M.; Carucci, P. Effect of COVID-19 Pandemic on

Hepatocellular Carcinoma Diagnosis: Results from a Tertiary Care Center in North-West Italy. Curr. Oncol. 2022, 29, 1422-1429. https://doi.org/ $10.3390 /$ curroncol29030119

Received: 20 January 2022

Accepted: 23 February 2022

Published: 24 February 2022

Publisher's Note: MDPI stays neutral with regard to jurisdictional claims in published maps and institutional affiliations.

Copyright: (C) 2022 by the authors. Licensee MDPI, Basel, Switzerland. This article is an open access article distributed under the terms and conditions of the Creative Commons Attribution (CC BY) license (https:// creativecommons.org/licenses/by/ $4.0 /)$.

\begin{abstract}
The COVID-19 pandemic has forced us to direct most of the available resources towards its management. This has led to the neglect of all other pathologies, including cancer. The aim of this study was to verify whether the difficulty in accessing the health system has led to a reduction in new diagnoses of hepatocellular carcinoma (HCC) and whether this has already been reflected in a more advanced stage of the cancer. A single-center, retrospective study including adult patients with a new diagnosis of HCC was performed. Patients were divided into three groups: the prelockdown phase (May 2019-February 2020), the lockdown phase (March 2020-December 2020), and the postlockdown phase (January 2021-October 2021); 247 patients were included. The number of patients diagnosed with HCC distinctly diminished in the periods March 2020-December $2020(n=69 ;-35 \%)$ and January 2021-October $2021(n=72 ;-32 \%)$ as compared to the period May 2019-February 2020 $(n=106)$. Noteworthy was the reduced surveillance in the period January 2021-October 2021 as compared to May 2019-February 2020 (22.9\% vs. 36.6\%, $p=0.056)$. No significant changes have yet been observed in tumor characteristics (BCLC staging distribution remained unvaried, $p=0.665$ ). In conclusion, the number of new HCC diagnoses decreased sharply in the first 2 years of the pandemic, with no worsening of the stage. A more advanced stage of the disease could be expected in the next few years in patients who have escaped diagnosis.
\end{abstract}

Keywords: SARS-CoV-2; ultrasound; alcohol; multifocal; nodule; Europe; cirrhosis; HBV; HCV; NAFLD

\section{Introduction}

The COVID-19 pandemic has hit our societies and forced us to radically change our priorities [1,2]. This was especially true during lockdown periods, when even access to hospitals was limited to urgent cases $[3,4]$. This has led to suboptimal and delayed management of all other diseases [5]. Oncological pathologies have been particularly affected, and delays have been documented in screenings, referrals, diagnoses, therapy, and follow-up [6].

Hepatocellular carcinoma (HCC) is one of the most common cancers worldwide, and it is also a primary cause of cancer-related death [7]. The World Health Organization (WHO) predicts that over 1 million people will die from HCC in 2030 [8]. The WHO estimates that $0.1 \%$ of the European population suffers from liver cirrhosis, with a calculated 170,000 deaths annually; HCC is responsible for 47,000 deaths annually [9]. In Italy, mortality 
from liver cirrhosis and HCC is approximately 8.1 and 8.8 per 100,000 inhabitants, respectively [10]. Ultrasound screening in patients at risk of HCC allows diagnosis at an early stage of disease with a beneficial impact on survival [11].

The organization of the management of liver cancer patients has certainly changed during the pandemic [12]. In an online survey in Asia updated in May 2020, it was reported that there has been a $26.7 \%$ decrease in HCC diagnoses compared to the prepandemic period [13]. On the other hand, therapeutic management of patients diagnosed with HCC in the early months of pandemic (2020) appears to have been maintained at an adequate level [14], but although these previous studies have been fundamental, they have significant limitations. Notably, no data were collected to demonstrate whether the COVID-19 pandemic had adverse effects on the stage of HCC at diagnosis.

From this, it can be inferred that the difficulty in accessing the health system has led to a decline in the number of new HCC diagnoses, but it is not yet known whether this has already had an impact on the disease stage.

The aim of our study was to compare the number of new diagnoses of HCC before the pandemic with that during the first and second years of the COVID-19 pandemic and to assess whether a more advanced stage of HCC can already be observed.

\section{Materials and Methods}

\subsection{Patients}

This retrospective study included adult patients ( $\geq 18$ years old) with a new diagnosis of HCC, recruited from 1 May 2019 to 31 October 2021 at the Gastroenterology Unit "Città della Salute e della Scienza di Torino-Molinette Hospital", Turin, Italy; this is the largest hospital and university facility in the city (and in the region), with about 1900 beds, and a regional reference center for HCC; the city of Turin has 7 other minor hospitals and a population of approximately 887,000 inhabitants.

Ultrasound surveillance of patients affected by liver disease was not carried out in our clinic but was carried out by hepatologists from other centers or general practitioners. As our hospital is a third-level center, we received patients with suspected or newly diagnosed HCC, mainly found during six-monthly ultrasound screening (slightly less than $40 \%$ ) or occasionally found in known or unknown liver disease (approximately $45-50 \%$ ) or in the course of hepatic decompensation (10-15\%). Patients with relapse of previously diagnosed HCC or with other primary liver tumors (i.e., cholangiocarcinoma) or liver metastasis were excluded from the study.

For the purpose of the study, patients were divided into three groups according to the time of HCC diagnosis: the prelockdown phase (May 2019-February 2020), the lockdown phase (March 2020-December 2020), and the postlockdown phase (January 2021-October 2021). Furthermore, the number of patients referred to our clinic with a new diagnosis of HCC was recovered from 1 January 2011. A specific database has been created for the collection of demographic, clinical, virological, and biochemical information. The presence of cirrhosis was determined by liver biopsy, liver elastography (FibroScan, Echosens, Paris, France), and/or hepatic ultrasound features and endoscopic signs of portal hypertension [15,16]. The diagnosis of HCC was achieved by histological examination or by contrast-enhanced imaging methods showing the radiological hallmark of HCC (i.e., the combination of hypervascularity in late arterial phase and washout on portal venous and/or delayed phases), according to international guidelines $[17,18]$. HCC was classified according to Barcelona Clinic Liver Cancer (BCLC) staging system $(0$ = very early; $\mathrm{A}=$ early; $\mathrm{B}=$ intermediate; $\mathrm{C}=$ advanced; $\mathrm{D}=$ end-stage $)$ [17].

Study procedures were compliant with the principles of the Declaration of Helsinki. All patients gave their written informed consent, and the study was approved by the Ethics Committee of the Città della Salute e della Scienza-University Hospital of Turin (approval code 2CEI-452; 6 June 2012). 


\subsection{Statistical Analysis}

Continuous variables were reported by median and interquartile range (IQR) while categorical variables were reported as number $(n)$ and percentage $(\%)$. Data normality was checked by the D'Agostino-Pearson test. Comparison between unpaired groups was performed by the Mann-Whitney test for continuous variables and by the chi-squared $\left(\chi^{2}\right)$ test for categorical variables, while comparison of continuous variables between more than two groups was performed by Kruskal-Wallis test. Linear regression analysis was performed to analyze the trend of the number of HCC diagnoses over time.

Since there is no study in the literature comparing the number of new diagnoses of HCC during lockdown, after lockdown, and before the COVID-19 pandemic, it was not possible to calculate the sample size in advance.

A two-tailed $p$ value $<0.05$ was considered statistically significant. All the statistical analyses were performed using MedCalc software, version 18.9.1 (MedCalc bvba, Ostend, Belgium).

\section{Results}

\subsection{Characteristics of the Study Cohort}

Overall, 247 patients with a new diagnosis of HCC were included in the study (from 1 May 2019 to 31 October 2021). The median age was $64.0(56.0-71.8)$ years, and the patients were predominantly males $(n=199 ; 80.6 \%)$. The main underlying liver disease etiology was viral $(n=142 ; 57.5 \%)$ and the prevalence of cirrhosis was $96.4 \%(n=238)$; the majority $(n=179 ; 75.5 \%)$ had a compensated liver disease (Child-Pugh score A). In most patients $(n=224 ; 91.4 \%)$, the diagnosis of HCC was obtained by imaging methods. Regarding tumor characteristics, 145 (58.7\%) patients were diagnosed with an early tumor (BCLC $0 / \mathrm{A})$; extrahepatic spread was detected in eight (3.2\%) patients.

The principal demographic, clinical, and biochemical characteristics of the patients included in the study are reported in Table 1.

Table 1. Characteristics of the patients included in the study according to the different periods of enrollment.

\begin{tabular}{|c|c|c|c|c|c|c|c|c|}
\hline Variables & Overall & $\begin{array}{c}\text { March 2020- } \\
\text { December } 2020\end{array}$ & $\begin{array}{c}\text { March 2020- } \\
\text { December 2020 }\end{array}$ & $\begin{array}{l}\text { January 2021- } \\
\text { October } 2021\end{array}$ & $p$ Value ${ }^{\mathrm{A}}$ & $p$ Value $^{\mathrm{B}}$ & $p$ Value $^{\mathrm{C}}$ & $p$ Value $^{\mathrm{D}}$ \\
\hline Patients $(n)$ & 247 & 106 & 69 & 72 & & & & \\
\hline $\begin{array}{l}\text { Age (years), median } \\
\text { (IQR); (247) }\end{array}$ & $\begin{array}{c}64.0 \\
(56.0-71.8)\end{array}$ & $64.0(55.0-73.0)$ & $63.0(56.0-69.5)$ & $\begin{array}{c}64.5 \\
(58.0-70.0)\end{array}$ & 0.600 & 0.439 & 0.316 & 0.850 \\
\hline $\begin{array}{l}\text { Gender }(\mathrm{M} / \mathrm{F}), n(\%) \text {; } \\
(247)\end{array}$ & $199(80.6 \%)$ & $79(74.5 \%)$ & $57(82.6 \%)$ & $63(87.5 \%)$ & $0.029^{\wedge}$ & 0.211 & 0.416 & $0.035^{\wedge}$ \\
\hline $\begin{array}{l}\text { BMI }\left(\mathrm{kg} / \mathrm{m}^{2}\right) \text {, median } \\
(\mathrm{IQR}) ;(247)\end{array}$ & $\begin{array}{c}26.1 \\
(23.3-29.4)\end{array}$ & $25.5(22.7-28.8)$ & $26.1(23.1-29.1)$ & $\begin{array}{c}26.9 \\
(23.8-30.5)\end{array}$ & 0.074 & 0.429 & 0.170 & $0.025^{\wedge}$ \\
\hline \multicolumn{9}{|l|}{ Etiology, $n(\%) ;(247)$ * } \\
\hline $\mathrm{HCV}$ & $116(47.0 \%)$ & $51(48.1 \%)$ & $34(49.3 \%)$ & $31(43.1 \%)$ & 0.539 & 0.881 & 0.461 & 0.508 \\
\hline HBV & $34(13.8 \%)$ & $16(15.1 \%)$ & $6(8.7 \%)$ & $12(16.7 \%)$ & 0.880 & 0.213 & 0.158 & 0.778 \\
\hline Alcohol & $96(38.9 \%)$ & $42(39.6 \%)$ & $27(39.1 \%)$ & $27(37.5 \%)$ & 0.781 & 0.948 & 0.843 & 0.776 \\
\hline NAFLD & $65(26.3 \%)$ & $18(17.0 \%)$ & $18(26.1 \%)$ & $29(40.3 \%)$ & $<0.001^{\wedge}$ & 0.147 & 0.075 & $0.001^{\wedge}$ \\
\hline Other & $19(7.7 \%)$ & $10(9.4 \%)$ & $8(11.6 \%)$ & $1(1.4 \%)$ & 0.069 & 0.647 & $0.014^{\wedge}$ & 0.029 \\
\hline $\begin{array}{l}\text { Viral etiology, } n(\%) \text {; } \\
\text { (247) }\end{array}$ & $142(57.5 \%)$ & $64(60.4 \%)$ & $40(58.0 \%)$ & $38(52.8 \%)$ & 0.600 & 0.752 & 0.538 & 0.316 \\
\hline $\begin{array}{l}\text { Platelet count }\left(\times 10^{9} / \mathrm{L}\right) \text {, } \\
\text { median }(\mathrm{IQR}) ;(241)\end{array}$ & $126(84-85)$ & $125(86-184)$ & $113(74-181)$ & $141(103-193)$ & 0.180 & 0.275 & 0.073 & 0.312 \\
\hline $\begin{array}{l}\text { Albumin (g/dL), } \\
\text { median (IQR); (190) }\end{array}$ & $4.0(3.4-4.4)$ & $3.8(3.3-4.4)$ & $4.1(3.5-4.4)$ & $4.0(3.4-4.3)$ & 0.446 & 0.240 & 0.658 & 0.409 \\
\hline $\begin{array}{l}\text { Total bilirubin (mg/dL), } \\
\text { median (IQR); (232) }\end{array}$ & $1.0(0.7-1.7)$ & $1.0(0.6-1.6)$ & $1.2(0.7-1.8)$ & $1.0(0.7-1.9)$ & 0.382 & 0.173 & 0.720 & 0.400 \\
\hline $\begin{array}{l}\text { AFP }(\mathrm{ng} / \mathrm{mL}), \text { median } \\
\text { (IQR); (196) }\end{array}$ & $7.6(3.3-101.5)$ & $5.8(3.6-122.6)$ & $8.1(2.8-105.7)$ & $9.2(3.1-75.1)$ & 0.930 & 0.843 & 0.787 & 0.737 \\
\hline Cirrhosis, $n(\%) ;(247)$ & $238(96.4 \%)$ & $101(95.3 \%)$ & $67(97.1 \%)$ & $70(97.2 \%)$ & 0.475 & 0.550 & 0.966 & 0.515 \\
\hline $\begin{array}{l}\text { Semestral surveillance, } \\
n(\%) ;(238)^{* *}\end{array}$ & $77(32.4 \%)$ & $37(36.6 \%)$ & $24(35.8 \%)$ & $16(22.9 \%)$ & 0.070 & 0.915 & 0.097 & 0.056 \\
\hline $\begin{array}{l}\text { Child-Pugh score, } n \\
(\%) ;(237)\end{array}$ & & & & & 0.968 & 0.777 & 0.922 & 0.925 \\
\hline A & $179(75.5 \%)$ & $78(77.2 \%)$ & $48(72.7 \%)$ & $53(75.7 \%)$ & & & & \\
\hline $\mathrm{B}$ & $52(21.9 \%)$ & $21(20.8 \%)$ & $16(24.2 \%)$ & $15(21.4 \%)$ & & & & \\
\hline C & $6(2.5 \%)$ & $2(2.0 \%)$ & $2(3.0 \%)$ & $2(2.9 \%)$ & & & & \\
\hline
\end{tabular}


Table 1. Cont.

\begin{tabular}{|c|c|c|c|c|c|c|c|c|}
\hline Variables & Overall & $\begin{array}{c}\text { March 2020- } \\
\text { December } 2020\end{array}$ & $\begin{array}{c}\text { March 2020- } \\
\text { December 2020 }\end{array}$ & $\begin{array}{l}\text { January 2021- } \\
\text { October } 2021\end{array}$ & $p$ Value $^{\mathrm{A}}$ & $p$ Value $^{\mathrm{B}}$ & $p$ Value $^{\mathrm{C}}$ & $p$ Value $^{\mathrm{D}}$ \\
\hline $\begin{array}{l}\text { HCC diagnostic test, } n \\
(\%) ;(245)\end{array}$ & & & & & 0.692 & 0.462 & 0.970 & 0.454 \\
\hline Liver biopsy & $21(8.6 \%)$ & $8(7.6 \%)$ & $6(8.7 \%)$ & $7(9.9 \%)$ & & & & \\
\hline $\begin{array}{l}\text { Magnetic } \\
\text { resonance }\end{array}$ & $76(31.0 \%)$ & $28(26.7 \%)$ & $24(34.8 \%)$ & $24(33.8 \%)$ & & & & \\
\hline $\begin{array}{l}\text { Computed } \\
\text { tomography }\end{array}$ & $148(60.4 \%)$ & $69(65.7 \%)$ & $39(56.5 \%)$ & $40(56.3 \%)$ & & & & \\
\hline $\begin{array}{l}\text { HCC nodules, } n(\%) \text {; } \\
(247)\end{array}$ & & & & & 0.331 & 0.105 & 0.722 & 0.227 \\
\hline 1 & $147(59.5 \%)$ & $56(52.8 \%)$ & $43(62.3 \%)$ & $48(66.7 \%)$ & & & & \\
\hline 2 & $31(12.6 \%)$ & $15(14.2 \%)$ & $11(15.9 \%)$ & $5(6.9 \%)$ & & & & \\
\hline 3 & $27(10.9 \%)$ & $14(13.2 \%)$ & $7(10.1 \%)$ & $6(8.3 \%)$ & & & & \\
\hline$>3$ & $42(17.0 \%)$ & $21(19.8 \%)$ & $8(11.6 \%)$ & $13(18.1 \%)$ & & & & \\
\hline $\begin{array}{l}\text { Major HCC nodule } \\
(\mathrm{mm}) \text {, median (IQR); } \\
(244)\end{array}$ & $\begin{array}{c}29.5 \\
(18.0-42.5)\end{array}$ & $27.0(16.5-45.5)$ & $28.0(20.0-39.3)$ & $\begin{array}{c}30.0 \\
(18.0-50.0)\end{array}$ & 0.887 & 0.933 & 0.657 & 0.675 \\
\hline $\begin{array}{l}\text { Extrahepatic spread, } n \\
(\%) ;(247)\end{array}$ & $8(3.2 \%)$ & $3(2.8 \%)$ & $2(2.9 \%)$ & $3(4.2 \%)$ & 0.637 & 0.979 & 0.685 & 0.629 \\
\hline BCLC, $n(\%) ;(247)$ & & & & & 0.665 & 0.375 & 0.642 & 0.707 \\
\hline 0 & $44(17.8 \%)$ & $17(16.0 \%)$ & $12(17.4 \%)$ & $15(20.8 \%)$ & & & & \\
\hline $\mathrm{A}$ & $101(40.9 \%)$ & $44(41.5 \%)$ & $32(46.4 \%)$ & $25(34.7 \%)$ & & & & \\
\hline $\mathrm{B}$ & $50(20.2 \%)$ & $19(17.9 \%)$ & $14(20.3 \%)$ & $17(23.6 \%)$ & & & & \\
\hline $\mathrm{C}$ & $48(19.4 \%)$ & $25(23.6 \%)$ & $9(13.0 \%)$ & $14(19.4 \%)$ & & & & \\
\hline $\mathrm{D}$ & $4(1.6 \%)$ & $1(0.9 \%)$ & $2(2.9 \%)$ & $1(1.4 \%)$ & & & & \\
\hline
\end{tabular}

Numbers in brackets indicate patients with available data. ${ }^{A}$ Comparison between the three groups; $p$ values were calculated by Kruskal-Wallis test for continuous variables and by $\chi^{2}$ test for categorical variables. ${ }^{\mathrm{B}}$ Comparison between the May 2019-February 2020 and March 2020-December 2020 periods; $p$ values were calculated by MannWhitney test for continuous variables and by $\chi^{2}$ test for categorical variables. C Comparison between the March 2020-December 2020 and January 2021-October 2021 periods; $p$ values were calculated by Mann-Whitney test for continuous variables and by $\chi^{2}$ test for categorical variables. D Comparison between the May 2019-February 2020 and January 2021-October 2021 periods; $p$ values were calculated by Mann-Whitney test for continuous variables and by $\chi^{2}$ test for categorical variables. ^ Statistically significant. * Patients could have more than one cause of chronic liver disease. Among patients with chronic HCV infection, 72 out of 116 (62.1\%) achieved SVR to previous antiviral treatment. Among patients with chronic HBV infection, 23 out of 34 (67.6\%) were under nucleoside or nucleotide analog therapy at the time of HCC diagnosis. ${ }^{*}$ Calculated in patients with a diagnosis of cirrhosis $(n=238)$. Abbreviations: alphafetoprotein (AFP), Barcelona Clinic Liver Cancer (BCLC), body mass index (BMI), female (F), hepatitis B virus (HBV), hepatocellular carcinoma (HCC), hepatitis C virus (HCV), international normalized ratio (INR), interquartile range (IQR), male (M), number (n), nonalcoholic fatty liver disease (NAFLD), ultrasound (US).

\subsection{Comparison between the Different Periods of Enrollment}

The number of patients diagnosed with HCC distinctly diminished in the periods March 2020-December $2020(n=69 ;-35 \%)$ and January 2021-October $2021(n=72 ;-32 \%)$ as compared to the period May 2019-February $2020(n=106 ; 100 \%)$. Consistently, analyzing data from 1 January 2011, we observed an increasing trend in the number of HCC diagnoses per 10-month interval until the COVID-19 pandemic (Figure 1), while in the last two periods the number of HCC diagnoses was lower than expected (Table 2). In accordance with these data, the median number of HCC diagnoses in the last two periods (March 2020-November 2021) was significantly lower than the median number of HCC diagnoses per 10-month interval since the COVID-19 pandemic (January 2011-February 2020) (median 70, IQR 60-72, vs. median 118, IQR 105-150, $p=0.030$, respectively).

Regarding characteristics of patients, we observed a stepwise increase in the prevalence of males over time, from $74.5 \%$ in the period May 2019-February 2020 to $82.6 \%$ in the period March 2020-December 2020 and 87.5\% in the period January 2021-October 2021 $(p=0.029)$. Interestingly, BMI significantly increased from May 2019-February 2020 to January 2021-October 2021 period (median 25.5, IQR $22.7-28.8 \mathrm{~kg} / \mathrm{m}^{2}$ vs. median 26.9, IQR $23.8-30.5 \mathrm{~kg} / \mathrm{m}^{2}, p=0.025$, respectively). 


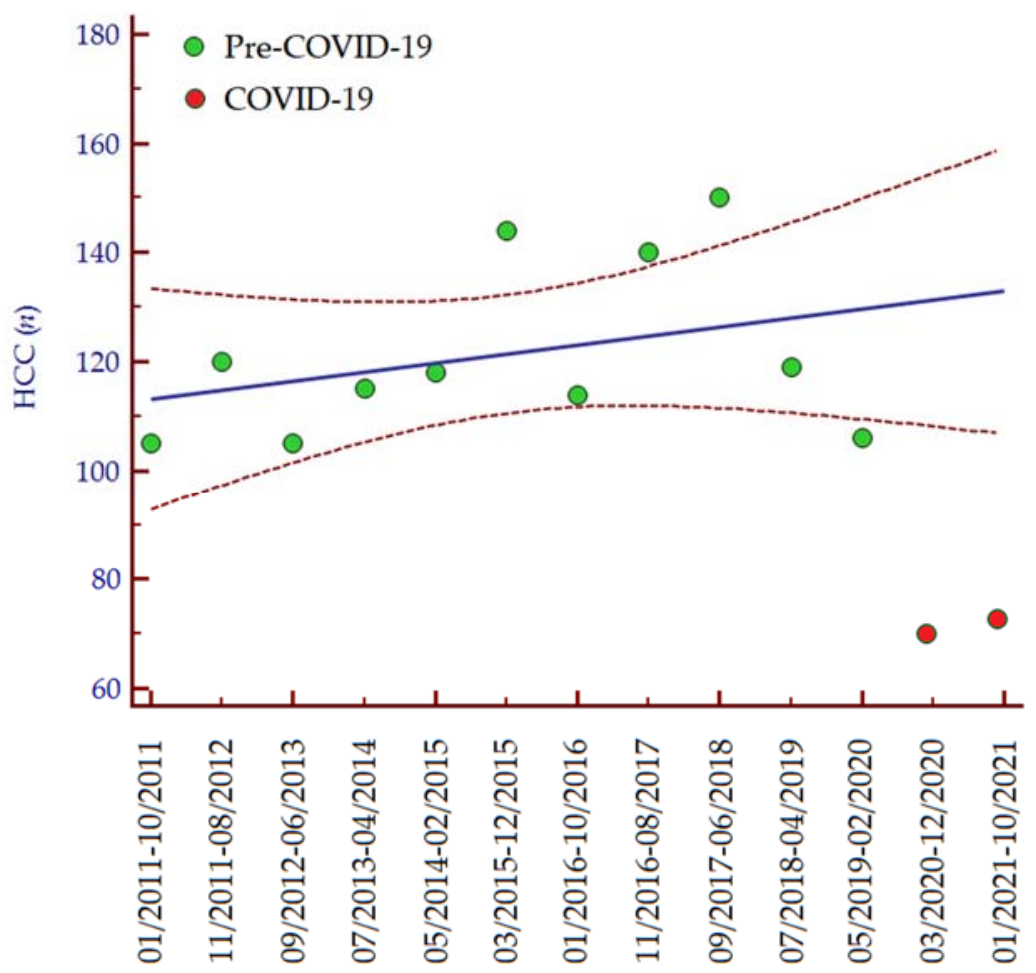

Figure 1. Number of HCC diagnoses per 10-month interval from 1 January 2011 to 31 October 2021. Regression equation: $y=111.527+0.165 * x$. The regression line is depicted in blue, while the $95 \%$ confidence interval of the regression line is depicted in red. Green dots indicate the number of patients diagnosed with HCC between January 2011 and February 2020, while the red dots indicate the number of patients diagnosed with HCC from March 2020 to October 2021. Abbreviations: coronavirus disease 19 (COVID-19), hepatocellular carcinoma (HCC), number $(n)$.

Table 2. Numbers of observed and expected diagnoses of HCC from 1 January 2011 to 31 November 2021.

\begin{tabular}{|c|c|c|c|c|c|c|c|c|c|}
\hline Time Period & $\begin{array}{c}\text { Observed } \\
\text { HCC } \\
\text { Diagnosis }(n)\end{array}$ & $\begin{array}{l}\text { Gender } \\
(\mathrm{M} / \mathrm{F})\end{array}$ & $\begin{array}{c}\text { Viral } \\
\text { Etiology } n \\
(\%)\end{array}$ & $\begin{array}{c}\operatorname{HCV} n \\
(\%)\end{array}$ & $\begin{array}{l}\operatorname{HBV} n \\
(\%)\end{array}$ & $\begin{array}{l}\text { Etiology * } \\
\text { Alcohol } n \\
\quad(\%)\end{array}$ & $\begin{array}{l}\text { NAFLD } n \\
(\%)\end{array}$ & $\begin{array}{l}\text { Other } n \\
(\%)\end{array}$ & $\begin{array}{c}\text { Expected HCC } \\
\text { Diagnosis }(n)^{* *}\end{array}$ \\
\hline January 2011-October 2011 & 105 & $81 / 24$ & $70(66.7 \%)$ & $59(56.2 \%)$ & $14(13.3 \%)$ & $37(35.2 \%)$ & $7(6.7 \%)$ & $7(6.7 \%)$ & \\
\hline $\begin{array}{l}\text { November 2011-August } \\
2012\end{array}$ & 120 & $95 / 25$ & $87(72.5 \%)$ & $67(55.8 \%)$ & $26(21.7 \%)$ & $38(31.7 \%)$ & $6(5.0 \%)$ & $11(9.2 \%)$ & \\
\hline September 2012-June 2013 & 105 & $82 / 23$ & $76(72.4 \%)$ & $65(61.9 \%)$ & $15(14.3 \%)$ & $33(31.4 \%)$ & $10(9.5 \%)$ & $5(4.8 \%)$ & \\
\hline July 2013-April 2014 & 115 & $86 / 29$ & $84(73.0 \%)$ & $67(58.3 \%)$ & $17(14.8 \%)$ & $44(38.3 \%)$ & $11(9.6 \%)$ & $2(1.7 \%)$ & \\
\hline May 2014-February 2015 & 118 & $93 / 25$ & $87(73.7 \%)$ & $72(61.0 \%)$ & $18(15.3 \%)$ & $38(32.2 \%)$ & $14(11.9 \%)$ & $6(5.1 \%)$ & \\
\hline $\begin{array}{c}\text { March 2015-December } \\
2015\end{array}$ & 144 & $111 / 33$ & $114(79.2 \%)$ & $94(65.3 \%)$ & $27(18.8 \%)$ & $60(41.7 \%)$ & $14(9.7 \%)$ & $5(3.5 \%)$ & \\
\hline January 2016-October 2016 & 114 & $86 / 28$ & $80(70.2 \%)$ & $70(61.4 \%)$ & $10(8.8 \%)$ & $32(28.1 \%)$ & $18(15.8 \%)$ & $5(4.4 \%)$ & \\
\hline $\begin{array}{l}\text { November 2016-August } \\
2017\end{array}$ & 140 & $114 / 26$ & $93(66.4 \%)$ & $83(59.3 \%)$ & $16(11.4 \%)$ & $59(42.1 \%)$ & $24(17.1 \%)$ & $3(2.1 \%)$ & \\
\hline September 2017-June 2018 & 150 & $117 / 33$ & $99(66.0 \%)$ & $81(54.0 \%)$ & $18(12.0 \%)$ & $62(41.3 \%)$ & $35(23.3 \%)$ & $9(6.0 \%)$ & \\
\hline July 2018-April 2019 & 119 & $93 / 26$ & $85(71.4 \%)$ & $69(58.0 \%)$ & $16(13.4 \%)$ & $52(43.7 \%)$ & $28(23.5 \%)$ & $5(4.2 \%)$ & \\
\hline May 2019-February 2020 & 106 & $79 / 27$ & $64(60.4 \%)$ & $51(48.1 \%)$ & $16(15.1 \%)$ & $42(39.6 \%)$ & $18(17.0 \%)$ & $10(9.4 \%)$ & \\
\hline $\begin{array}{c}\text { March 2020-December } \\
2020\end{array}$ & 69 & $57 / 12$ & $40(58.0 \%)$ & $34(49.3 \%)$ & $6(8.7 \%)$ & $27(39.1 \%)$ & $18(26.1 \%)$ & $8(11.6 \%)$ & 131 \\
\hline January 2021-October 2021 & 72 & $63 / 9$ & $38(52.8 \%)$ & $31(43.1 \%)$ & $12(16.7 \%)$ & $27(37.5 \%)$ & $29(40.3 \%)$ & $1(1.4 \%)$ & 133 \\
\hline
\end{tabular}

* Patients could have more than one cause of chronic liver disease. ${ }^{* *}$ Estimated by regression equation. Abbreviations: hepatocellular carcinoma (HCC), number $(n)$.

No variation was observed in the prevalence of cirrhosis $(p=0.475)$; consistently, no significant changes were observed in liver function parameters (platelet count, $p=0.180$; albumin, $p=0.446$; total bilirubin, $p=0.382$ ) and in Child-Pugh score $(p=0.968)$. Remarkably, we noticed an increase in dysmetabolic etiology of liver disease, with a prevalence of $17.0 \%$ in the period May 2019-February 2020 to a prevalence of $26.1 \%$ in the period March 2020-December 2021, to 40.3\% in the period January 2021-October 2021 
$(p<0.001)$. Noteworthy was the reduction in regular ultrasound surveillance reported by patients diagnosed with HCC in the period January 2021-October 2021 compared to those diagnosed in the period May 2019-February 2020 (22.9\% vs. 36.6\%, $p=0.056$ ).

No significant changes have yet been observed in the tumor characteristics. The number of patients with unifocal vs. multifocal HCC has remained stable over time $(p=0.331)$, as has the median size of HCC nodules $(p=0.887)$; in agreement with these findings, BCLC staging distribution has remained unchanged $(p=0.665)$.

\section{Discussion}

The five-year survival rate for HCC remains around $20 \%$, partly due to poor adherence to screening and subsequent diagnostic and therapeutic delay [19]. Restrictions on access to the healthcare system due to the COVID-19 pandemic priority are likely to have made early detection of new HCCs even less efficient.

The data in the literature regarding the new diagnoses of HCC during these 2 years of the COVID-19 pandemic are limited to the first months of 2020. In a study conducted in Austria, 28 patients were diagnosed with HCC in the first half of 2020. There was no difference in the number of diagnoses of HCC before and after the lockdown (14 vs. 14). After the lockdown, more patients were delayed in visits and imaging tests, but no information was available on the stage of HCC [20]. In France, a significant decrease in the rate of HCC patients referred for first diagnosis or treatment was observed in the first weeks of the pandemic, but no data on the effect of lockdown after months or years are known [21]. In a recent letter to the editor, authors found an increased prevalence of HCC in patients admitted to hospital in 2020 due to alcoholic hepatitis ( $\mathrm{OR}=1.19 ; 95 \% \mathrm{CI} 1.08-1.32)$ : these findings may indicate a decline in HCC outpatient diagnosis as a result of the COVID-19 outbreak, which has caused a delay or discontinuity in regular HCC surveillance [22].

Our study included a large sample $(n=247)$ of new HCC diagnosed in a third-level center from 1 May 2019 to 31 October 2021. The characteristics of patients diagnosed with HCC were analyzed in detail throughout the lockdown period (2020) and in the following year (2021). During the lockdown (March 2020-December 2020) and after the lockdown (January 2021-October 2021) we observed a clear (over 30\% decrease) and statistically significant reduction $(p=0.030)$ in the number of patients referred to our clinic for the first diagnosis of HCC compared to prepandemic period (May 2019-February 2020). It should be noted that our clinic did not apply any restriction to patients' access during the pandemic period.

We can hypothesize some possible reasons for the negative impact of COVID-19 on the diagnosis of patients with HCC. During the COVID-19 pandemic, the government imposed two restrictions: social separation and house confinement, both of which were widely followed. Hence, liver patients at increased risk of HCC may not have been able to reach our hospital for medical consultations or may have received unspecified general appointments without priority, and this probably mirrored the general situation in our region, entrusted to an oncology network.

The most important reason that could explain the reduction in the number of new diagnoses of HCC is the marked reduction in 6-month ultrasound surveillance in cirrhotic patients at risk of HCC (from $36.6 \%$ before the pandemic to $22.9 \%$ in the year following the onset of the pandemic), probably due to limited access to diagnostic tests.

Although a more advanced disease with a more severe prognosis is not yet evident (BCLC comparison $\rightarrow p=0.707$; no significant difference in the number of patients with unifocal vs. multifocal HCC $\rightarrow p=0.227$, as well as in the median size of HCC nodules $\rightarrow$ $p=0.675$ ), it is likely that we will find it when we diagnose HCC in $30-40 \%$ of patients who escaped diagnosis in these 2 years.

In our study, the prevalence of cirrhotic patients was slightly higher than that expected from the literature data (about 80\% [23]), but compatible with a cohort in which $\mathrm{HCV}$ is still the main cause [24], despite a progressive increase in NAFLD as a cause (or a contributing cause) of HCC (from $17 \%$ to about $40 \%$ ). This figure reflects the prediction 
that NAFLD will be the leading cause of HCC over the next decade [25], but it appears to have even worsened perhaps due to social restrictions and home confinement that limited physical activity; furthermore, we may have been more sensitive to reporting NAFLD as a contributing cause: in fact, its increase is not proportional to the decrease in viral infection, but is added to them. Our work presents some limitations, mainly that it is a retrospective, with limited sample size, and single-center study, which limits the applicability of our results: a validation of our results in a multicenter setting is mandatory. Strengths of our study include the following: it is the first study that analyzed a large number of new HCCs diagnosed during the first and second years of the pandemic and that has thoroughly analyzed the characteristics of patients with HCC in these 2 years.

\section{Conclusions}

In conclusion, our study shows that the COVID-19 pandemic had a significant impact on the number of patients at risk of HCC who have been diagnosed with cancer, although this did not result in more advanced HCC at diagnosis. Since HCC is a slow-growing cancer with a tumor doubling time of approximately 6 months, we expect the clinical consequences of a missed diagnosis to be more evident in the long-term follow-up.

Author Contributions: Conceptualization, D.G.R., G.P.C. and P.C.; methodology, D.G.R. and G.P.C.; software, D.C. and P.R.B.; validation, D.G.R., G.P.C. and P.C.; formal analysis, D.G.R. and G.P.C.; investigation, D.G.R., G.P.C., S.G., E.R., A.R., P.R.B., D.C. and P.C.; data curation, A.R., P.R.B. and D.C.; writing —original draft preparation, D.G.R. and G.P.C.; writing—review and editing, G.M.S., E.R., S.G., A.R. and P.C.; visualization, D.G.R. and G.P.C.; supervision, G.M.S.; project administration, P.C. All authors have read and agreed to the published version of the manuscript.

Funding: This research received no external funding.

Institutional Review Board Statement: The study was conducted in accordance with the Declaration of Helsinki and approved by the Institutional Ethics Committee of the Città della Salute e della Scienza-University Hospital of Torino (approval code 2CEI-452; 6 June 2012).

Informed Consent Statement: Informed consent was obtained from all subjects involved in the study.

Data Availability Statement: The data presented in this study are available upon request from the corresponding author.

Conflicts of Interest: The authors declare no conflict of interest.

\section{References}

1. Phillips, T.; Zhang, Y.; Petherick, A. A year of living distantly: Global trends in the use of stay-at-home orders over the first 12 months of the COVID-19 pandemic. Interface Focus 2021, 11, 20210041. [CrossRef]

2. Actis, G.C.; Pellicano, R.; Ribaldone, D.G. SARS-CoV-2: Impacts and Echoes. Rev. Recent Clin. Trials 2021. [CrossRef] [PubMed]

3. Wilson, G.; Windner, Z.; Dowell, A.; Toop, L.; Savage, R.; Hudson, B. Navigating the health system during COVID-19: Primary care perspectives on delayed patient care. N. Z. Med. J. 2021, 134, 17-27. [PubMed]

4. Actis, G.C.; Ribaldone, D.G.; Fagoonee, S.; Pellicano, R. COVID-19: A user's guide, status of the art and an original proposal to terminate viral recurrence. Minerva Med. 2021, 112, 144-152. [CrossRef] [PubMed]

5. Harber, I.; Zeidan, D.; Aslam, M.N. Colorectal Cancer Screening: Impact of COVID-19 Pandemic and Possible Consequences. Life 2021, 11, 1297. [CrossRef]

6. Jazieh, A.R.; Akbulut, H.; Curigliano, G.; Rogado, A.; Alsharm, A.A.; Razis, E.D.; Mula-Hussain, L.; Errihani, H.; Khattak, A.; De Guzman, R.B.; et al. Impact of the COVID-19 Pandemic on Cancer Care: A Global Collaborative Study. JCO Glob. Oncol. 2020, 6, 1428-1438. [CrossRef]

7. Fitzmaurice, C.; Akinyemiju, T.; Abera, S.; Ahmed, M.; Alam, N.; Alemayohu, M.A.; Allen, C.; Al-Raddadi, R.; Alvis-Guzman, N.; Amoako, Y.; et al. The Burden of Primary Liver Cancer and Underlying Etiologies From 1990 to 2015 at the Global, Regional, and National Level: Results From the Global Burden of Disease Study 2015. JAMA Oncol. 2017, 3, 1683-1691.

8. Villanueva, A. Hepatocellular Carcinoma. N. Engl. J. Med. 2019, 380, 1450-1462. [CrossRef]

9. Blachier, M.; Leleu, H.; Peck-Radosavljevic, M.; Valla, D.C.; Roudot-Thoraval, F. The burden of liver disease in Europe: A review of available epidemiological data. J. Hepatol. 2013, 58, 593-608. [CrossRef]

10. Ascione, A.; Fontanella, L.; Imparato, M.; Rinaldi, L.; De Luca, M. Mortality from cirrhosis and hepatocellular carcinoma in Western Europe over the last 40 years. Liver Int. 2017, 37, 1193-1201. [CrossRef] 
11. Kuo, S.C.; Lin, C.N.; Lin, Y.J.; Chen, W.Y.; Hwang, J.S.; Wang, J. Der Optimal Intervals of Ultrasonography Screening for Early Diagnosis of Hepatocellular Carcinoma in Taiwan. JAMA Netw. Open 2021, 4, e2114680. [CrossRef] [PubMed]

12. Muñoz-Martínez, S.; Sapena, V.; Forner, A.; Nault, J.C.; Sapisochin, G.; Rimassa, L.; Sangro, B.; Bruix, J.; Sanduzzi-Zamparelli, M.; Hołówko, W.; et al. Assessing the impact of COVID-19 on liver cancer management (CERO-19). JHEP Rep. 2021, 3 , 100260. [CrossRef] [PubMed]

13. Gandhi, M.; Ling, W.-H.; Chen, C.-H.; Lee, J.H.; Kudo, M.; Chanwat, R.; Strasser, S.I.; Zhu, X.; Lai, S.-H.; Chow, P.K.-H. Impact of COVID-19 on Hepatocellular Carcinoma Management: A Multicountry and Region Study. J. Hepatocell. Carcinoma 2021, 8, 1159-1167. [CrossRef] [PubMed]

14. Iavarone, M.; Antonelli, B.; Ierardi, A.M.; Topa, M.; Sangiovanni, A.; Gori, A.; Oggioni, C.; Rossi, G.; Carrafiello, G.; Lampertico, P. Reshape and secure HCC managing during COVID-19 pandemic: A single centre analysis of four periods in 2020 versus 2019. Liver Int. 2021, 41, 3028-3032. [CrossRef]

15. Caviglia, G.P.; Touscoz, G.A.; Smedile, A.; Pellicano, R. Noninvasive assessment of liver fibrosis: Key messages for clinicians. Pol. Arch. Med. Wewn. 2014, 124, 329-335. [CrossRef]

16. Gaia, S.; Campion, D.; Evangelista, A.; Spandre, M.; Cosso, L.; Brunello, F.; Ciccone, G.; Bugianesi, E.; Rizzetto, M. Non-invasive score system for fibrosis in chronic hepatitis: Proposal for a model based on biochemical, FibroScan and ultrasound data. Liver Int. 2015, 35, 2027-2035. [CrossRef]

17. Galle, P.R.; Forner, A.; Llovet, J.M.; Mazzaferro, V.; Piscaglia, F.; Raoul, J.L.; Schirmacher, P.; Vilgrain, V. EASL Clinical Practice Guidelines: Management of hepatocellular carcinoma. J. Hepatol. 2018, 69, 182-236. [CrossRef]

18. Caviglia, G.P.; Ciruolo, M.; Abate, M.L.; Carucci, P.; Rolle, E.; Rosso, C.; Olivero, A.; Troshina, G.; Risso, A.; Nicolosi, A.; et al. Alpha-fetoprotein, protein induced by vitamin $\mathrm{K}$ absence or antagonist II and glypican-3 for the detection and prediction of hepatocellular carcinoma in patients with cirrhosis of viral etiology. Cancers 2020, 12, 3218. [CrossRef]

19. Rao, A.; Rich, N.E.; Marrero, J.A.; Yopp, A.C.; Singal, A.G. Diagnostic and Therapeutic Delays in Patients With Hepatocellular Carcinoma. J. Natl. Compr. Cancer Netw. 2021, 19, 1063-1071. [CrossRef]

20. Pomej, K.; Scheiner, B.; Hartl, L.; Balcar, L.; Meischl, T.; Mandorfer, M.; Reiberger, T.; Müller, C.; Trauner, M.; Pinter, M. COVID-19 pandemic: Impact on the management of patients with hepatocellular carcinoma at a tertiary care hospital. PLoS ONE 2021, 16, e0256544. [CrossRef]

21. Amaddeo, G.; Brustia, R.; Allaire, M.; Lequoy, M.; Hollande, C.; Regnault, H.; Blaise, L.; Ganne-Carrié, N.; Séror, O.; Larrey, E.; et al. Impact of COVID-19 on the management of hepatocellular carcinoma in a high-prevalence area. JHEP Rep. Innov. Hepatol. 2021, 3, 100199. [CrossRef] [PubMed]

22. Perisetti, A.; Kaur, R.; Thandassery, R. Increased Diagnosis of Hepatocellular Carcinoma in Hospitalized Patients with Alcohol Related Hepatitis after the COVID-19 Outbreak: A Global Multi-Center Propensity Matched Analysis. Clin. Gastroenterol. Hepatol. 2021, 19, 2450-2451.e1. [CrossRef]

23. Desai, A.; Sandhu, S.; Lai, J.P.; Sandhu, D.S. Hepatocellular carcinoma in non-cirrhotic liver: A comprehensive review. World J. Hepatol. 2019, 11, 1-18. [CrossRef]

24. Perisetti, A.; Goyal, H.; Yendala, R.; Thandassery, R.B.; Giorgakis, E. Non-cirrhotic hepatocellular carcinoma in chronic viral hepatitis: Current insights and advancements. World J. Gastroenterol. 2021, 27, 3466-3482. [CrossRef] [PubMed]

25. Grgurevic, I.; Bozin, T.; Mikus, M.; Kukla, M.; O’beirne, J. Hepatocellular Carcinoma in Non-Alcoholic Fatty Liver Disease: From Epidemiology to Diagnostic Approach. Cancers 2021, 13, 5844. [CrossRef] [PubMed] 